\title{
Cochlear Implantation in Chronic Otitis Media
}

\author{
Charlotte M. Chiong ${ }^{1,2}$ and Elaine C. Villanueva ${ }^{2}$ \\ ${ }^{1}$ Philippine National Ear Institute, National Institutes of Health, University of the Philippines, Manila \\ ${ }^{2}$ Department of Otorhinolaryngology, College of Medicine and Philippine General Hospital, University of the Philippines, Manila
}

\begin{abstract}
Objectives. The objectives of this study are to describe the experience on cochlear implantation among patients with chronic otitis media (COM) and to describe the management of patients with otitis media before and after cochlear implantation $(\mathrm{Cl})$.

Methods. The records of one hundred five consecutive patients who have undergone cochlear implantation were reviewed and the patients with chronic otitis media either before or after surgery were included in the study. Data such as age at implantation, etiology of deafness, laterality of otitis media, radiologic studies, medications and intraoperative findings in these patients were reviewed then recorded in a separate database file. Outcomes in terms of complications during or after surgery were likewise noted.
\end{abstract}

Results. Of 105 patients who had cochlear implantation, twelve patients had history of chronic otitis media or recurrent acute otitis media. There were three patients, 2 adults with bilateral COM as the cause for deafness and one child with bilateral COM and middle ear foreign body mimicking a cholesteatoma. All three had to undergo mastoidectomy and tympanoplasty for the surgical management of active suppurative chronic otitis media. No further episodes of otitis media were noted and all were otitis free subsequently at the time of cochlear implantation. Five prelingually deaf children had otitis media following cochlear implantation (one week to 4 months), two of whom had to undergo revision cochlear implant surgery without explantation for definitive management. Four additional patients had episodes of recurrent otitis media prior to and after cochlear implantation which required only medical management with broad spectrum antibiotics.

Conclusion. Despite high prevalence of otitis media in the Philippines, our data supports literature reports that cochlear implantation is a safe and effective procedure in patients with bilateral profound hearing loss both in the pediatric and adult

Presented at the 7th Asia Pacific Symposium on Cochlear Implant and Related Sciences (APSCI), Dec. 1-4, 2009, Singapore.

Corresponding author: Charlotte M. Chiong, MD

Philippine National Ear Institute

National Institutes of Health

University of the Philippines Manila

623 Pedro Gil Street, Ermita, Manila 1000 Philippines

Telephone: +632 5548400 loc. 2072

Email: charlotte_chiong@yahoo.com population. A close follow up of these patients is recommended given the higher risk of otitis media in children, especially since the age that $\mathrm{Cls}$ are being performed becomes younger. It should also be emphasized that adequate counseling of parents and caregivers regarding the possible post-operative complications in cochlear implant recipients should be done before the procedure in the context of local experience. Bilateral simultaneous cochlear implantation has the added advantage that patients continue to hear in one ear even if complications may occur on the other side allowing unimpeded speech rehabilitation especially in the critical stage of language development following $\mathrm{Cl}$.

Key Words: cochlear implantation, chronic otitis media, otitis media, hearing loss

\section{Introduction}

Profound hearing loss can be accompanied by or result from chronic otitis media. The World Health Organization defines CSOM as a chronic inflammation of the middle ear and mastoid cavity, which presents with recurrent otorrhea through a perforated tympanic membrane. The disease usually begins in childhood as a spontaneous tympanic membrane perforation due to an infection of the middle ear. $\mathrm{COM}$ is one of the most common of the preventable causes of deafness which in developing countries comprise about fifty percent. As of 2004, the regional prevalence of chronic otitis media in the Philippines is deemed to be high at between $2-4 \%{ }^{1}$

Cochlear implant technology continues to develop rapidly and such technological evolution resulted in expanded indications to include younger children. This represents the current treatment of choice for patients affected by severe to profound sensorineural hearing loss (SNHL). Patient selection is based on pre-implantation protocol consisting of otologic and audiologic evaluation, imaging of the temporal bone using high resolution computed tomography and magnetic resonance imaging, an assessment of communicative ability, behavioral and developmental evaluation. ${ }^{2}$ Cochlear implantation was first introduced in the country in 1997 and the first two postlingually deafened patients were implanted at the Philippine General Hospital in 1998. At the time of this review, more than a hundred cochlear implantations have been performed in our institute comprising more than half of the total cochlear implantations performed in the country. 
Historically, the presence of otitis media (OM) on initial evaluation or a history of chronic or recurrent $\mathrm{OM}$ has represented a relative risk factor for increased complications after cochlear implant surgery.3,4 Presumably, the introduction of a foreign device in an infected mastoid cavity or middle ear puts the patient at risk for possible intracranial spread of infection following cochlear implantation. However, the well established benefits of cochlear implantation and improved surgical and radiologic techniques have resulted in several reports demonstrating the safety and feasibility of cochlear implantation even in patients with COM. ${ }^{5}$

Otitis media is not only a concern during the preoperative stage, but also postoperatively. The onset of otitis media in children following cochlear implantation can be a cause for concern given the possibility that $\mathrm{OM}$ in implanted patients may lead to meningitis or other intracranial complications. It is thus important to review our local experience with respect to the presence of chronic otitis media in candidates for $\mathrm{CI}$ as well as the onset of COM or recurrent otitis media after $\mathrm{CI}$ in our patients.

\section{Methods}

A total of 105 cochlear implantations in 94 patients with a variety of etiologic causes of bilateral severe to profound hearing loss have been surgically performed by the senior author (CMC) from Oct. 1998-Oct. 2009 (Figure 1). All patients were administered prophylactic antibiotics consisting of intravenous Cefuroxime at $50 \mathrm{mg} / \mathrm{kg} /$ day given at induction of anesthesia and continued for 48 hours postoperatively in the hospital prior to discharge. A retrospective review of the medical records of all cochlear implantees was done. The demographics reviewed included sex, side and age of implantation, otoscopic findings, duration of deafness prior to implantation, audiologic tests, radiologic (high resolution CT scan and MRI) findings, and history of previous ear infections or surgery. Twelve patients were identified to have otitis media either chronic or recurrent prior to or after cochlear implantation. These patients were divided into three groups: those with chronic otitis media prior to cochlear implantation (group A), recurrent otitis media before and after implantation (group B), and patients who developed otitis media related complications after implantation (group C). Table 1 shows the demographic characteristics of the patients and HRCT/ MRI findings. Pre-implantation evaluation included high resolution $\mathrm{CT}$ of the temporal bone aimed at determining possible presence of cochlear malformation or detecting possible presence of subclinical middle ear infections that might impact on the outcome of cochlear implantation in these cases. For example in one patient there was evidence of labyrinthine ossification characteristic of meningitis and entailed the use of special short electrodes as recommended for cases of obliteration in the cochlear turns by either soft fibrous tissue or even bone. This is to optimize the generally poorer outcomes of $\mathrm{CI}$ in post-meningitic cases. Fibrosis and modified anatomy following a previous mastoid and middle ear surgery require special consideration with the prospect of more difficult CI surgery as experienced in this series. Table 2 shows patients with otitis media cases with the management and outcome.

Table 1. Demographic characteristics of the patients and HRCT/ MRI Findings

\begin{tabular}{|c|c|c|c|c|c|c|}
\hline Patient & Age/Gender & $\begin{array}{c}\text { Etiology of } \\
\text { hearing loss }\end{array}$ & $\begin{array}{c}\text { Duration of } \\
\text { Deafness Years }\end{array}$ & Implant Side & $\begin{array}{l}\text { CT scan of the } \\
\text { temporal bone }\end{array}$ & $\begin{array}{l}\text { MRI of the brain } \\
\text { and the inner ear }\end{array}$ \\
\hline 1 & $2 / \mathrm{M}$ & Rubella & 2 & Left & Acute mastoiditis, Right & Normal \\
\hline 2 & $4 / \mathrm{M}$ & $\begin{array}{l}\text { Meningitis } \\
\text { Ototoxicity }\end{array}$ & 4 & Left & Mildly dilated vestibules & Normal \\
\hline 3 & $47 / \mathrm{M}$ & CSOM & 11 & Right & $\begin{array}{l}\text { Bilateral mastoiditis with } \\
\text { cholesteatoma }\end{array}$ & Normal \\
\hline 4 & $3 / F$ & Rubella & 4 & $\begin{array}{c}\text { Bilateral } \\
\text { simultaneous }\end{array}$ & Normal & - \\
\hline 5 & $4 / \mathrm{M}$ & LVAS & 4 & Left & $\begin{array}{l}\text { Mild right otitis media, } \\
\text { Large Vestibular Aqueduct } \\
\text { Syndrome considered }\end{array}$ & - \\
\hline 6 & $3.8 / \mathrm{F}$ & $\begin{array}{c}\text { Rubella } \\
\text { COM }\end{array}$ & 3 & Right & Bilateral mastoiditis & Normal \\
\hline 7 & $2 / \mathrm{M}$ & $\begin{array}{l}\text { Rubella } \\
\text { LVAS }\end{array}$ & 2 & Left & $\begin{array}{l}\text { Large Vestibular Aqueduct } \\
\text { Syndrome }\end{array}$ & $\begin{array}{c}\text { Bilateral dilated vestibular } \\
\text { aqueducts; right cerebellopontine } \\
\text { angle cistern cyst }\end{array}$ \\
\hline 8 & $5 / \mathrm{M}$ & Rubella & 5 & $\begin{array}{c}\text { Bilateral } \\
\text { simulataneous }\end{array}$ & Normal & - \\
\hline 9 & $5 / \mathrm{M}$ & Unkown & 5 & Right & Minimal mastoiditis & Normal \\
\hline 10 & $1 / \mathrm{M}$ & Meningitis & 1 & Right & $\begin{array}{l}\text { Bilateral labyrinthine } \\
\text { ossification }\end{array}$ & Normal \\
\hline 11 & $3 / F$ & $\begin{array}{l}\text { Waardenburg } \\
\text { Syndrome }\end{array}$ & 3 & Right & $\begin{array}{l}\text { Bilateral deformed cochlea } \\
\text { and enlarged vestibules }\end{array}$ & $\begin{array}{c}\text { Absence of posterior semicircular } \\
\text { canals }\end{array}$ \\
\hline 12 & $44 / \mathrm{M}$ & $\begin{array}{l}\text { Labyrinthitis } \\
2^{\circ} \mathrm{CSOM}\end{array}$ & 4 & Left & $\begin{array}{c}\text { Bilateral mastoiditis } \\
\text { changes with recurrent } \\
\text { mastoiditis }\end{array}$ & $\begin{array}{c}\text { Bilateral mastoiditis with possible } \\
\text { changes of right sided } \\
\text { labyrinthitis }\end{array}$ \\
\hline
\end{tabular}


Table 2. Otitis media cases with the management and outcome

\begin{tabular}{|c|c|c|c|c|}
\hline Patient & $\begin{array}{c}\text { Onset of OM } \\
\text { (pre- or post-implantation) }\end{array}$ & Duration of onset & $\begin{array}{l}\text { COM Management } \\
\text { (Medical or Surgical) }\end{array}$ & Management Details \\
\hline 1 & Pre- & Unknown & Medical & \\
\hline 2 & Pre- & 5 months & Medical & Co-amoxiclav \\
\hline 3 & Pre- & $\begin{array}{l}\text { MRM Tympanoplasty done } 4 \\
\text { years prior to implant }\end{array}$ & Surgical & Mastoidectomy, bilateral \\
\hline 4 & Post- & 6 months & Medical and Surgical & Revision CI (blind sac closure, mastoid obliteration) \\
\hline 5 & Pre- & unknown & Medical & Unknown \\
\hline 6 & Pre- & 1 year & Surgical & tympanoplasty, R; middle ear exploration, $\mathrm{L}$ \\
\hline 7 & Pre-/Post- & $\begin{array}{l}\text { pre implant/ } 1 \text { month post } \\
\text { implant }\end{array}$ & Medical & $\begin{array}{l}\text { No record pre/ } \\
\text { co-amoxiclav, cefuroxime post implant }\end{array}$ \\
\hline 8 & Post- & 4 months & Medical and Surgical & $\begin{array}{l}\text { Revision CI } \\
\text { (Mastoidectomy, debridement with resetting of } \\
\text { receiver }\end{array}$ \\
\hline 9 & Pre-/Post- & $\begin{array}{l}1 \text { month pre-implant } \\
1 \text { week post-implant }\end{array}$ & Medical & Co-amoxiclav \\
\hline 10 & Pre-/Post- & $\begin{array}{l}2.5 \text { months pre implant/ } 3 \\
\text { months post implant }\end{array}$ & Medical & Cefuroxime \\
\hline 11 & Pre- & 3 months pre implant & Medical & Cefaclor \\
\hline 12 & Pre- & $\begin{array}{l}\text { MRM tym panoplasty done } \\
11 \text { months prior to implant }\end{array}$ & Surgical & Mastoidectomy, bilateral \\
\hline
\end{tabular}

\section{Results}

There were 105 cochlear implantations done on 94 patients as of October 2009. The etiology of hearing loss in the majority comprised congenital rubella in about $36 \%$ (Figure 1). Notably COM was the cause of deafness in $4 \%$. There were 12 patients (13\%) with either chronic or recurrent otitis media prior to or after CI subclassified into three groups: a) three patients with chronic otitis media prior to CI, b) 7 patients with pre-implant otitis media with three patients continuing to have bouts of otitis media even after $\mathrm{CI}$ and c) two patients who had otitis media-related complications after CI. There were 2 adults and 10 children affected. The mean age of the adult patients is 45.5 years and 4.5 years for the pediatric group at the time of implantation. Of the twelve implanted patients, 7 were done on the right, 3 on the left, while 2 patients in this series had simultaneous or single stage bilateral implantation.

Group A patients had a first stage canal up mastoidectomy and tympanoplasty for management of active COM that was performed prior to $\mathrm{CI}$, which was done as a second stage. This included two adults (Patients 3, 12) with COM as the cause of deafness. While the etiology in one patient was unclear and presumably bacterial, in the other patient, a previously dry bilateral tympanic membrane perforation converted to active disease with granular tissue formation and subsequent bilateral profound hearing loss after the patient was fitted with customized in the canal hearing aids by a hearing aid dispenser. The cochlear implantation surgery was rendered difficult by the anatomic alterations and fibrosis and the patient had severe postoperative vertigo that prolonged hospital confinement for one week. The third patient in this group was a child who had bilateral chronic otitis media. She initially underwent simultaneous surgeries in both ears with a canal up mastoidectomy with tympanoplasty in the right and a middle ear exploration with myringoplasty in the left ear. Interestingly there was note of a rubber foreign body from a pencil eraser in the left epitympanum. Subsequently left cochlear implantation was performed uneventfully.

Group B included four patients who had otitis media with effusion prior to implantation (Patients 1, 2, 5, 11). One had tympanocentesis prior to the surgery; all were medically treated with systemic antibiotics. In addition, there were 3 patients who had recurrent otitis media prior to and after CI (Patients 7, 9, 10) who were all successfully treated medically with combined topical and systemic antibiotics.

Finally, Group C included two children (Patients 4 and 8) who both underwent bilateral simultaneous cochlear implantation then developed otitis media leading to complications that necessitated revision surgery without explantation. In the first patient, revision surgery consisted of middle ear obliteration and blind sac closure of the external auditory canal and Eustachian tube obliteration for the management of active COM with actual visualization of the electrode through a central tympanic membrane perforation. The other patient underwent myringotomy with incision and drainage but electrode exposure from a wound dehiscence was followed by debridement and subsequent repositioning of the receiver in a new bed after removal of granulation tissue (Figure 2). These patients continue to be monitored but have had no further problems up to 8 years of follow-up. Both implantees fortunately had the contralateral implanted ear working such that speech and hearing rehabilitation continued. Both patients have been mainstreamed to a regular school with intelligible speech and good speech and language development as of last follow up after six and eight years, respectively. 


\section{Cause of Deafness}

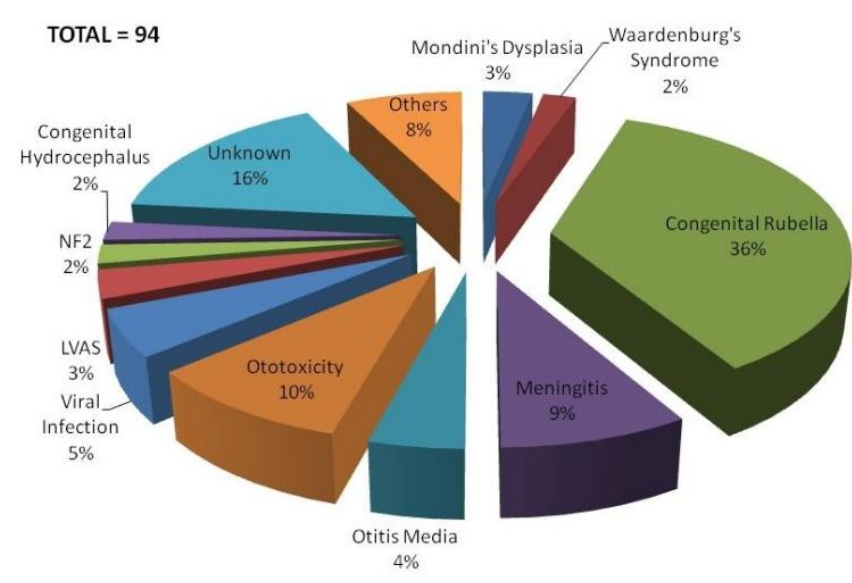

Figure 1. Etiology of deafness among cochlear implantees in the Philippines

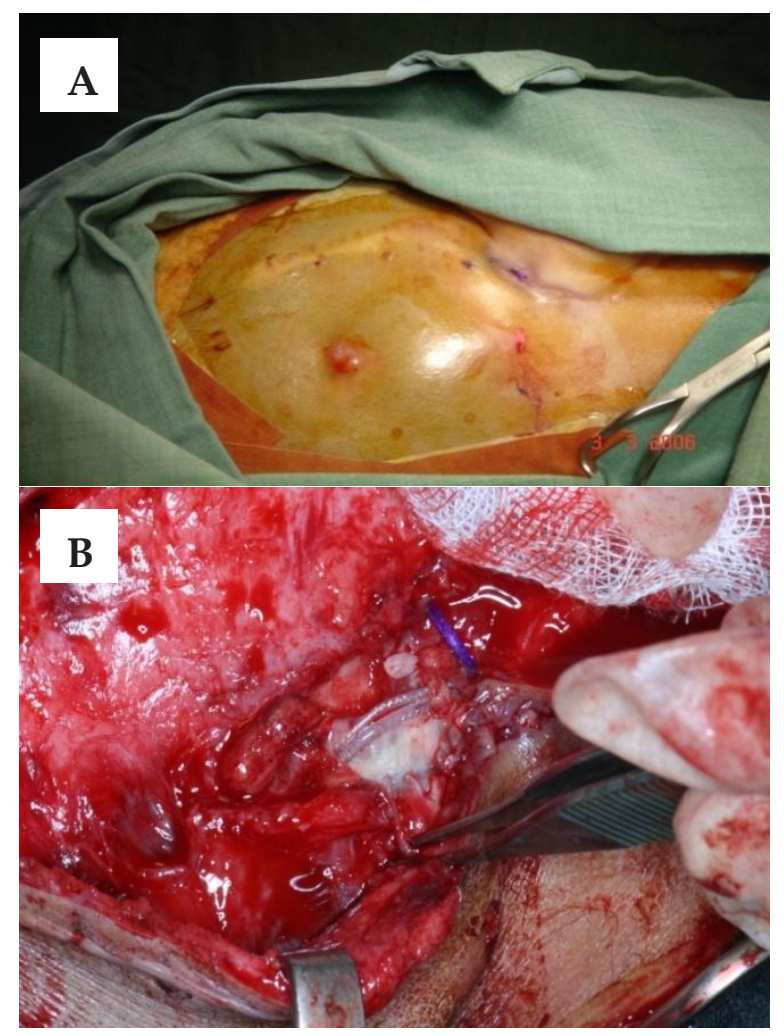

Figure 2. Intraoperative picture of patient with the electrode exposure from the post auricular wound dehiscence (A) and granulation tissue that has lifted the implant receiver from its bed (B)

\section{Discussion}

In 1996, the World health Organization classified the Philippines as a country with a high chronic otitis media prevalence rate $(2-4 \%) .{ }^{1}$ Otitis media can produce cochlear damage and cause deafness as seen in $4 \%$ of our cochlear implantees. The overall incidence of otitis media related to CI was $12 \%$ in this series. Potentially ototoxic bacterial endotoxins or exotoxins and local treatment agents such as aminoglycosides have been reported to cause inner ear damage and the progression of sensorineural hearing loss in these patients.

Although the benefits of early restoration of hearing and rehabilitation in children have been well described, the placement of an implant in an inflammed or potentially infected middle ear and mastoid represents a theoretical risk for intracranial infection, complications of implant extrusion and bacterial contamination of the implant requiring removal. ${ }^{6}$ In 1986, a history of chronic otitis media and suppurative labyrinthitis constituted relative contraindications in doing cochlear implantation, and cases of profound deafness secondary to chronic otitis media with extensive cholesteatoma were likewise contraindicated.3,5,6 However, later studies reported the benefit of CI in the setting of COM.

Chronic otitis media as seen in this series, can lead to major complications necessitating revision surgery. The incidence or severity of otitis media following implantation could be greater in cochlear implantation. This stems from the notion that otitis media could cause the implanted internal coil and electrode in the mastoid and the middle ear to become an infected foreign body with biofilm formation. The infection might extend along the electrode into the inner ear, possibly resulting in meningitis and further degeneration of the auditory system. ${ }^{6,7}$ Infections can even be potentially lethal with onset of meningitis complications or sepsis. None of the patients in this series had to be explanted despite the need for revision surgery for OM related complications.

Presently, the age at which CI is performed in children generally corresponds to the age when prevalence of $\mathrm{OM}$ is highest. It is therefore, safe to assume that in pediatric CI recipients, the risk of problematic middle ear infection along the electrode array into the cochlea and the central nervous system are relatively higher. It has been established that the younger the age at CI, the more rapid the gain in speech perception. Therefore, the usual practice of trying to limit $\mathrm{OM}$ management in the general pediatric population to conservative care, where the time factor is an important element in overcoming age susceptibility to OM, may not be advisable to OM-prone CI candidates. The deferral might reduce the potential for maximum benefit from the implant. Of 60 patients reported by Luntz, OM-prone CI candidates were significantly younger than their healthy counterparts by an average of 13.6 months at the time of implantation. ${ }^{8}$ Comparing the age of patients who received $\mathrm{CI}$ in relation to the timing of their otitis media seem to suggest that those with recurrent otitis (pre and post $\mathrm{CI}$ ) were younger than 
those who had OM either before or after CI by an average of 7 months in this series.

Other studies ${ }^{6,10}$ have shown that the incidence of otitis media does not increase after implantation. Cochlear implantation should not alter the naturally progressive decrease in the incidence of otitis media in children. In 1985, House and co-workers stated both parents and doctors reported no increase in incidence and severity of otitis media in children following cochlear implantation. ${ }^{6}$ Luntz also reported a reduction of prevalence of otitis media presumably due to a variety of factors including selection of candidates who have had otitis media controlled preoperatively, the natural tendency for incidence to decrease with age, the use of intraoperative prophylactic antibiotic intravenously and from cavity irrigation, and the effect of mastoidectomy. ${ }^{10}$ In the present report, two patients had complications requiring revision surgery without OM-related intracranial complications. In other studies of $\mathrm{OM}$ and $\mathrm{CI}$, the occurrence of intracranial complications was minimal. ${ }^{6,11}$

Acute otitis media or acute mastoiditis in the implanted ear should be treated just like unimplanted ears and when OM does occur after $\mathrm{CI}$, the number of severe complications is usually small and can be effectively treated with routine antibiotics. In our series, only 5 patients had complications after implantation. Of these cases, two had delayed onset of otitis media, and one had early onset otitis media (one week after surgery). All three cases were adequately controlled with oral high dose broad-spectrum antibiotics and did not need hospital confinement. The other two patients, however, had major delayed onset complications. One patient (patient 4), whose electrode could be visualized through the perforated tympanic membrane, had to undergo a radical mastoidectomy with blind sac ear canal closure with mastoid obliteration. The other patient, who initially presented with acute otitis media (patient 8) had eventual electrode exposure from a post-auricular wound dehiscence, underwent incision and drainage with myringotomy then eventual revision surgery with implant repositioning after debridement. The cochlear implant devices were not explanted in these two patients.

Cochlear implantation in chronic otitis media with or without cholesteatoma has been performed in many centers locally and abroad. In patients with simple, dry perforations, some authors graft the perforation during cochlear implantation surgery as a single stage procedure, but others prefer a two-stage surgery. In patients with chronically discharging ear or with cholesteatoma, most surgeons prefer to stage the procedure. The first stage entails clearing the disease with or without obliteration of the mastoid cavity, and cochlear implantation is done as a second stage procedure. ${ }^{9,12}$

El Kashlan et al. favored non-obliteration of the cavity as this allows better visualization of the cavity radiologically with high resolution computerized tomography, which should eliminate the concern for cholesteatoma and avoid a second look surgical procedure. He also concluded that cochlear implantation could be safely achieved as a single stage procedure in patients with chronic suppurative otitis media. ${ }^{5}$ In contrast, Incesulu et al., reported that for infected radical cavities, a two stage operation is reasonable. ${ }^{13}$ Opening all the mastoid air cells, blind sac closure of the external auditory canal and Eustachian tube and obliteration of the mastoid cavity are performed in the first stage. If there is no sign of infection after three to six months, cochlear implantation may then be performed. Obliteration materials, such as autologous abdominal fat graft, hydroxyapatite and tricalcium phosphate, cartilage and temporalis muscle, may be used in the cavity. Among these, abdominal fat graft and temporalis muscle are the most common obliteration materials, autologous fat having the advantage of being obtained in large amounts and with greater resistance to necrosis and contraction.

We adopted a two-stage procedure in the 3 patients who had COM prior to implantation ( 2 adults, 1 child). Of the adult patients, one had a canal up mastoidectomy 4 years prior to implant and the other had the same procedure 11 months before cochlear implantation. The pediatric patient underwent a tympanoplasty on the right, nine months prior to cochlear implantation on that side, and middle ear exploration on the left ear. None of them showed recurrence of infections during an average follow-up period of 55 months. Two pediatric patients who received bilateral cochlear implantation with no prior history of otitis media developed CSOM months after and required a surgical procedure to control the infection. Gram staining and culture studies in both cases were negative. There was no evidence of foreign body giant cells on histopathologic examination in both cases. Likewise, explantation of the device was not carried out. While the latter may be considered controversial, the possibility of saving implants in such clinical situations has been cited by other surgeons. ${ }^{14}$ Incidentally, as both patients who underwent revision surgery had bilateral cochlear implantation even while they had to undergo surgery to control infection in one of their implanted ears, benefit from the contralateral ear continued and was unimpeded. It was reported by Papsin and Gordon that simultaneous and short delayed sequential implants in children are most likely to be cost effective and should be considered for rehabilitation in children with bilateral severe to profound sensorineural hearing loss so that children receive the best chance for development of speech and language by minimizing the interval of bilateral deafness. ${ }^{15}$ The added advantage, as shown in our two patients, is that when otitis media related complications do occur in one ear, hearing rehabilitation is unimpeded in the contralateral ear. 


\section{Conclusion}

Cochlear implantation is proven as a safe and effective procedure in patients with bilateral profound hearing loss both in the pediatric and adult population even in our country where the prevalence of chronic otitis media remains high. Close follow up of these patients is recommended given the higher risks of otitis media in children since the age when CIs are being performed has become younger. Adequate preoperative counseling of parents and caregivers regarding the possible complications in cochlear implant recipients including the need for revision surgery should be done. Saving a working device in the setting of severe infection can be safely done as we have shown. Bilateral simultaneous cochlear implantation has an added advantage in that patients continue to hear in one ear even if complications may occur on the other side allowing unimpeded speech rehabilitation especially in the critical stage of language development following CI.

Two-stage procedures for eradication of the active COM prior to definitive $\mathrm{CI}$ effectively prepared the ears for subsequent CI given that no further recurrence of otitis media were noted in all three deaf patients who had to undergo mastoidectomy with tympanoplasty for control of active chronic otitis media prior to CI. These ears therefore remained to be safe even with the cochlear implant-in-situ. The high prevalence of COM in the Philippines remains to be a valid concern so that efforts in prevention should be sustained even while emerging technologies like CI continue to develop as a viable solution for the treatment of profound hearing loss especially in otitis prone young deaf children in this country.

\section{References}

1. World Health Organization Child and Adolescent Health and Development. Prevention of Blindness and Deafness. Geneva, 2004. Chronic Suppurative Otitis Media: Burden of Illness and Management. [Online]. 2004 [cited 2012 July]. Available from http://www.who.int/pbd/deafness/activities/hearing_care/otitis_media.p df.

2. Chiong CM. Cochlear Implantation: The Philippine General Hospital Experience. Philipp J Otolaryngol Head Neck Surg. 2001; 16(1):9-13.

3. Belal A Jr. Contraindications to cochlear implantation. Am J Otol. 1986; 7(3):172-5.

4. Gray RF, Irving RM. Cochlear implants in chronic suppurative otitis media. Am J Otol. 1995; 16(5):682-6.

5. El-Kashlan HK, Arts HA, Telian SA. Cochlear implantation in chronic suppurative otitis media. Otol Neurotol. 2002; 23(1):53-5.

6. House WF, Luxford WM, Courtney B. Otitis media in children following the cochlear implant. Ear Hear.1985; 6(3 Suppl):24S -26S.

7. Migirov L, Yakirevitch A, Henkin Y, Kaplan-Neeman R, Kronenberg J. Acute otitis media and mastoiditis following cochlear implantation. Int J Pediatr Otorhinolaryngol. 2006; 70(5):899-903.

8. Luntz M, Teszler CB, Shpak T, Feiglin H, Farah-Sima'an A. Cochlear implantation in healthy and otitis-prone children: a prospective study. Laryngoscope. 2001; 111(9):1614-8.

9. Kim CS, Chang SO, Lee HJ, Shim WS, Oh SH, Kim YH. Cochlear implantation in patients with a history of chronic otitis media. Acta Otolaryngol. 2004; 124(9):1033-8.
10. Luntz M, Hodges AV, Balkany T, Dolan-Ash S, Schloffman J. Otitis media in children with cochlear implants. Laryngoscope. 1996; 106(11):1403-5.

11. Luntz M, Teszler CB, Shpak T. Cochlear implantation in children with otitis media: second stage of a long term prospective study. Int J Pediatr Otorhinolaryngol. 2004; 68(3):273-80.

12. Basavaraj S, Shanks M, Sivaji N, Allen AA. Cochlear implantation and management of chronic suppurative otitis media: single stage procedure? Eur Arch Otorhinolaryngol. 2005; 262(10):852-5.

13. Incesulu A, Kocaturk S, Vural M. Cochlear implantation in chronic otitis media. J Laryngol Otol. 2004; 118(1):3-7.

14. Leach J, Kruger P, Roland P. Rescuing the imperiled cochlear implant: a report of four cases. Otol Neurotol.2005; 26(1):27-33.

15. Papsin BS, Gordon KA. Bilateral cochlear implants should be the standard for children with bilateral sensorineural deafness. Curr Opin Otolaryngol Head Neck Surg. 2008; 16(1):69-74. 